\title{
Study of Teachers' Intervention on Conflicts between Preschoolers
}

\author{
Qiumeng $\mathrm{Hu}$ \\ Chongqing University of Education \\ Chongqing, China
}

\author{
Lamei Luo \\ Chongqing University of Education \\ Chongqing, China
}

\begin{abstract}
To solve conflicts between preschoolers is one of the important factors to measure the development of children's social ability. The children who have high-level ability of solving conflicts between preschoolers will be good with the peers. And the social development is better. Teachers are important to infants. Teachers' views on conflicts between preschoolers and the way of intervention will directly affect the effectiveness of solving conflicts between preschoolers. By means of literature study, this paper combs teachers' intervention on conflicts between preschoolers. And it finds that the research has not formed an effective scheme to intervene conflicts between preschoolers. Also, it lacks the research on improving teachers' ability to intervene conflicts between preschoolers. The teachers are less involved in the intervention research of conflicts between preschoolers. Therefore, the author would make the following empirical research from several aspects.
\end{abstract}

Keywords-conflicts between preschoolers; teacher; response; intervention; summary

\section{INTRODUCTION}

Peer conflict is a common phenomenon in children's social intercourse. It has been thought that peer conflict is beneficial to the development of children and an important form of social intercourse [10], which can speed up the socialization process of children. Conflict is the main motive force of change, adjustment and development [13]. Peer conflicts enable children gradually to be "decentralized". They would reduce egoism, deepen mutual understanding, and gradually learn to coordinate each other according to social norms [5]. At the same time, it can also promote the development of children's morality. Children will gradually develop the sense of fairness when solving the conflict. It would lay the foundation for children to understand the social routine, and improve the ability to solve social problems [2]. Teachers play an important role in the process of conflict. Teachers' reasonable intervention can effectively improve the level of solving peer conflict [8]. However, many studies have found that there are still some shortcomings in teachers' awareness of concern and ability of guidance in solving peer conflict [1].

\section{RESEARCH ON TEACHERS' INTERVENTION ON CONFLICTS BETWEEN PRESCHOOLERS}

\section{A. Teachers' Views on Conflicts between Preschoolers and Its Value}

Every kindergarten teacher will encounter many conflicts between preschoolers in teaching and daily activities. Teachers hold different views and attitudes to these conflicts. Some studies have found that kindergarten teachers may be hostile to conflicts between preschoolers. Also, they may neglect conflicts between preschoolers. Or they would be powerlessness. They also pay attention and other attitudes to conflicts between preschoolers.

1) Teachers believe that peer conflict is not conducive to child development: Some teachers believe that conflict is a negative concept. It is not an opportunity for students to learn and grow. They are hostile to conflict and do not want to see conflicts between children. These teachers can prevent conflicts among young children by reducing the amount of time they play freely. They often emphasize the use of rules. And they would take activities to prevent the conflicts [1]. There are also many teachers who believe that children's conflicts happen quickly and end quickly. Many conflicts will end in the end. If the two sides do not act or speak excessively during the conflict, the whole process looks peaceful. And the teachers will ignore it. However, conflict resolution plays a very important role in the development of children. Teachers' negligent attitude leads to the loss of many educational opportunities, which is not conducive to the improvement of solving conflicts between preschoolers and the development of social skills [7]

2) Teachers gradually realize the importance of peer conflict: The educators gradually realize the importance of conflict resolution to children. They often attach more importance to children's studies than conflict resolution. Harris (2002) points out those kindergarten teachers often focus on teaching their children academic skills rather than social skills. Many kindergarten teachers and administrators believe that grades in subjects such as math and reading are more important. And conflict resolution education for children deviates from the learning of academic skills. If teachers teach conflict resolution, they will reduce their time 
in other subjects. They often have intentional and powerless attitude. In the end, the children can naturally develop the ability of solving the conflicts. However, many teachers began to realize the rationality of conflict and the importance of conflict resolution to children's social development [3]. These teachers often actively respond to children's conflict, pay attention to children's emotions and needs in conflict resolution, and help children to solve the conflict smoothly in a guiding way rather than leading way [6].

From the above, it can be seen that teachers' views on conflict and its value will influence their role in solving conflicts between preschoolers. Of course, if teachers can attach importance to conflict and recognize the importance and value of conflict resolution to young children's development, they will respond to the conflict more actively, guide them to learn high-level conflict resolution strategies, and promote the development of their social capabilities.

\section{B. Teachers' Intervention Mode of Conflicts between Preschoolers}

Teachers pay different attention to conflicts between preschoolers. They also have different ways to intervene in the conflict. Many studies have made a more detailed classification from the exterior behaviors of teachers' intervention and the nature of the intervention methods. Wang Weiqing (1995) divided teachers' response to conflicts between preschoolers into three types: non-response, indirect intervention and direct intervention [4]. Non-response refers that teachers would ignore children seeking the help or simply nods and uses other ways to deal with conflict. And the children cannot get any information in this process. Indirect intervention means that teachers decentralize power to children. The children convey their ideas and suggestions. The children mainly rely on themselves to deal with conflicts. On the other hand, teachers would end the expression to deal with the conflicts. Direct intervention is to help children to solve the conflict through question, comfort, solution and other ways.

Most scholars divide it from the nature of the strategy. Betsy (2002) argues that there are two traditional ways of adult dealing with the child conflict: authoritative way and evasive way. Jenkins et al. (2008) made a further classification; think that teachers' response to conflicts between preschoolers has three kinds: avoidance, coercion and cooperation. Educators who adopt avoidance strategies believe that they will avoid intervention completely if the children are peace with their actions in conflict. However, they have also missed many educational opportunities, which are not conducive to the development of young children's social capabilities. Educators who adopt coercive strategies argue that such strategies can produce results quickly. However, they also deny children the chance to learn to resolve conflicts. With the use of coercive strategies, teachers use authority and continued control to separate the parties to the conflict. And they do not allow the children to become an active part in the process. The cooperative strategy is the conflict resolution strategy that kindergarten teachers want to master most. They empathize and choose views in the process. In this conflict situation and conflict strategy, teachers can play the role of mediator [7]. Chinese researcher Zhao Kai (2007) points out that there are four types of teachers' responses in the context of conflicts between preschoolers: inspiration and guidance, information and demonstration, decision-making and perfunctory control. It was further pointed out that the distribution of various reaction types was uneven, with $42 \%$ of decision-making, $29 \%$ of perfunctory control, $11 \%$ of inspiration and guidance and $18 \%$ of information and demonstration, respectively.

Some scholars have analyzed the teachers' response strategies from the concrete peer conflict situations. Pang Lijuan and Tao Sha (1997) point out that when children compete for toys, teachers have the following reactions: to criticize both sides; to "suppress" the party; to divert children's attention; to investigate the cause excessively; to put away the disputed toys; preaching; to leave it alone. The purpose of these response styles is to end the conflict as soon as possible, without considering whether the young child can accept it or what the young child can learn in the process.

Through the above research, we find that teachers are not too positive to response to peer conflict. They compulsorily judge the right and wrong. And the social skills and emotional development of children are negative. [6] There are studies suggesting that if a teacher tells a child to be friendly when he or she is in conflict, or tells him to share toys with everyone to solve the problem, the conflict immediately ended. However, the children do not understand what kind of behavior is friendly behavior. At the next time, they still don't know how to perform in the same situation. The children knew what was wrong in this situation. They did not learn effective strategies and skills to deal with the mistake. At the next time, when they encountered the same situation, they might steal something from someone else.

\section{STUDY ON TEACHER'S INTERVENTION ON CONFLICTS BETWEEN PRESCHOOLERS}

\section{A. Teachers' Preliminary Experience Intervention on Conflicts between Preschoolers}

From the previous literature, it can be seen that peer conflicts often occur. The children lack constructive strategies to solve the conflicts. Long time ago, many schools and related organizations have begun to focus on conflict resolution and peer mediation training. According to the studies, the early conflict resolution is often referred to the training in a class, grade or school. Conflict resolution is to teach students to control anger, avoid aggressive reactions, enable them to understand conflict and avoid potential physical violence in conflict. Many schools in the four states of the United States (Florida, Maryland, Missouri, and North Carolina) have conducted peer mediation training for students in conflict resolution. However, due to factors such as the level of child violence, the cost of interventions, the time students and managers spent, and the effective ways needed in large-scale projects, some training are often abandoned halfway. And some trainings are not tested effectively [11]. It is regrettable. 
However, the exploration of improving the level of peer conflict resolution strategies has not stopped. Some studies have found that children can grasp the high level of conflict resolution strategies through reasonable intervention and guidance. The children can constructively resolve peer conflicts, and enhance peer friendship. At the same time, it is conducive to the improvement of academic achievement and good adaptation to school life [8]. Follow-up studies also found that children also tried to use conflict resolution strategies learned in real conflict. At the same time, students who learn to mediate will also mediate the conflict between other peers. Teachers also believed that there was a significant reduction in peer conflict in trained classes, and the ability of children to use negotiation and mediation was significantly higher than that of untrained students [14].

\section{B. Initial Plan of Teachers' Intervention on Peer Conflict}

Through the analysis of these guiding methods and experimental intervention schemes, we can see that the schemes are designed according to the rules of children's development. These guiding methods and schemes have their similarities, which deserve our reference and can be summed up as follows: (1) Let both sides of the conflict calm down as much as possible; (2) let them express their feelings and thoughts; (3) further exchanges between the parties of the conflict promote mutual understanding and empathy (i.e. taking views); (4) to make both sides of the conflict or viewers think of solutions as far as possible to enhance the subjectivity of the participants; (5) In the end, we choose the acceptable way to settle the conflict smoothly, peer interaction can continue. Whether the target is pupils, junior high school students or young children, the basic intervention ideas and steps are like this.

This article focuses on the development of Johnson's conflict resolution strategy and intervention program. Their total scheme, named "Teaching students to be peacemakers", began in the 1960s with a series of studies around the scheme. They have established an intervention network in schools in the countries of United States, Europe and Asia. And their conflict intervention schemes have grown and developed in schools in these regions and countries. In order to test the effectiveness of the scheme, they conducted 12 studies focusing on conflict mediation training schemes in primary and junior and senior secondary schools, which were evaluated over a period of several months to a year. The study was conducted in schools in cities and suburbs. The subjects rank from junior to senior students in different races and cultures. Thus, the study was highly reliable. Their research is done strictly according to the experimental study, and the effect is relatively obvious. It has very high intrinsic and extrinsic validity [9].

And this study will draw lessons from the peer conflict resolution of Stevahn \& Johnson (2000) in the kindergarten implementation. In the study, it is called comprehensive negotiation six-step method. The experiment was conducted in the preschool part of a school. The subjects were 5-yearold and 6-year-old students, including two classes taking part in the morning course and two classes taking part in the afternoon course. One morning class and one afternoon class were randomly selected from these classes as the experimental classes, and the others were the control classes. These young children are from middle-class families, and their academic development is roughly the same. The teachers in the experimental class and the control class rotate every two days, which controls the teacher's influence on the results of the experiment. Conflict resolution was introduced into the teaching of friendship in the experimental class. However, there is no such an introduction in the control class. The experiment lasted four weeks. The teachers would give half an hour of friendship teaching each day. And the children would take a total of nine hours of schooling. The teaching contents of the experimental class include: (1) what the conflict is and what the concept of conflict is; (2) A comprehensive consultative approach that includes six steps for constructive conflict resolution, which is the result of study of Johnson \& Johnson in 1995. Specifically, they would be aware of the conflict and have willingness to resolve it constructively. And they should state what they want; state the reasons, express one's feelings, and state one's own understanding of the thoughts and reasons of others. They should develop three or more alternatives based on the principle of the best interests of both parties. And they should choose a solution to reach agreement, shake hands and make peace. The intervention results can provide key ideas and specific operational tools for this study.

\section{COMMENT ON EXISTING RESEARCH}

Researches have been made on the use of peer conflict resolution strategies. Teachers have made rich studies on intervention methods and the guidance of peer conflict resolution strategies, which provide some useful references for later research. However, the following shortcomings have also been identified from previous studies.

\section{A. Effective Schemes for Intervention on Conflicts between Preschoolers Have not Been Developed}

Researchers have paid more attention to and studied the specific "points" of peer conflict resolution strategies, such as the types of peer conflict resolution strategies, the level and effectiveness of conflict resolution strategies. However, these points are not separated. The research on the main conflict resolution strategies used by children, the level of these strategies, the results of using different levels of strategies, and the influence of these strategies on children's intercourse need to be strengthened.

\section{B. It Lacks Research on Improving Kindergarten Teachers' Ability to Intervene in Peer Conflict}

Researchers believe that teachers' awareness of children's peer conflict resolution strategies and guidance ability is insufficient, which has negative impact on the improvement of children's peer conflict resolution strategies. However, the research on improving teachers' awareness of concern and guidance ability is still deficient. Therefore, to improve teachers' level and ability of peer conflict resolution strategies through intervention, and to promote the level and effectiveness of peer conflict resolution strategies have more research space. 


\section{An Intervention Study on Kindergarten Teachers' Less Participation in Peer Conflict}

Researchers have been found to intervene in peer conflict resolution strategies. And the groups of teachers are the real educational guides. Teachers in the ordinary teaching activities and teaching management mainly rely on their own experience to explore ways to promote conflict resolution. However, after many years of research and practice abroad, Betsy (2002) proposed the six-step conflict resolution method. It is specially used to guide teachers to promote children's conflict resolution reasonably. And it has achieved remarkable results. Also, it has good reliability and validity. And it is especially worthy of reference and application. However, there is no relevant research and practical application in China at present.

\section{CONCLUSION}

One of the major manifestations of children's social development is the ability to solve the peer conflict. Reasonable teacher intervention can effectively improve the level of children's peer conflict resolution. To this, domestic and foreign scholars pay much attention to it, and they have made a detailed study. Researchers have done a lot of research on the performance of peer conflict, the types of conflict resolution strategies, the factors affecting conflict resolution strategies and so on. However, there are few studies on improving preschool teachers' intervention on peer conflict reasonably. This paper combs the literatures of teachers' intervention on peer conflict of children. Through the later empirical research, we can enrich the achievements, form complete effective intervention program, improve the professional quality of kindergarten teachers, and further promote the harmonious development of children's physical and mental health.
[7] Jenkins,S.,Ritblatt,S.,\&McDonald,J.S.(2008). Conflict resolution among early childhood educators. Conflict Resolution Quarterly,25(4),429-450

[8] Johnson, D. W., \& Johnson, R. (1991). Teaching students to be peacemakers. http://www.co-operation.org/pages/peacemaker.html

[9] Johnson,D.W.,Johnson,R.T.,\&Dudley,B.(1992). Effects of peer mediation training on elementary school students. Mediation Quarterly,10(1),89-99

[10] Laursen,B., Finkelstein,B.D.,\&Betts,N.T.(2001). A developmental meta-analysis of peer conflict resolution. Developmental Review, 21, 423-449

[11] Powell,K.E.,Muir-McMlain,L.,Halasyamani,L.(1995). A review of selected school-based conflict resolution and peer mediation projects. The Journal of School Health,65(10),426-431

[12] Ram,A.,\&Ross,h.S.(2001). Problem solving, contention, and struggle: How siblings resolve a conflict of interests. Child development, 72(6),1710-1722

[13] Shantz,C.U.(1987). Conflicts between children. Child Development, 58, 283-305

[14] Stevahn,L.,Johnson,D.W.,Johnson,R.T.,Laginski,A.M.,\&O’Coin,I.(1 996). Effects on high school students of integrating conflict resolution and peer mediation training into an academic unit. Mediation Quarterly,14(1),21-36

[15] Stevahn,L.,Johnson,D.W.,Johnson,R.T.,Oberle,K.,\&Wahl,L.(2000). Effects of conflict resolution training integrated into a kindergarten curriculum. Child Development,71(3), 772-784

\section{REFERENCES}

[1] Jiang Qiufang. Study on middle-class conflicts between preschoolers and coping strategies [D]. Master's Law Thesis, Nanjing Normal University, 2007. 蒋秋芳. 中班幼儿同伴冲突及应对策略研究 [D]．南京师范法学硕士学位论文, 2007

[2] Liu Xiaojing. Research on the behavior of conflicts between preschoolers [D]. Master's Law Thesis, Nanjing Normal University, 2002. 刘晓静. 幼儿同伴冲突行为研究 [D] . 南京师范大学硕 士学位论文, 2002

[3] Wu Jinhong. A study of teacher education behavior in conflicts between preschoolers [D]. Master's Thesis of Southwest University, 2008. 仵金红. 幼儿同伴冲突中教师教育行为研究 [D] . 西南 大学硕士学位论文, 2008

[4] Zhao Kai. Study on the characteristics and types of teacher's responses in conflicts between preschoolers [D]. Master's Thesis of Beijing Normal University, 2007. 赵凯. 幼儿同伴冲突情境中教师 反应的特点与类型的研究 [D]. 北京师范大学硕士学位论文, 2007

[5] Chang Juanjuan. Conflicts between preschoolers and its solution strategy [J]. Journal of Educational Development, 2008(6): 24-26. 常 娟娟. 幼儿同伴冲突及其解决策略 [ J ] . 教育导刊, 2008 (6) : 24-26

[6] Betsy Evans. You can't come to my birthday party. High/Scope Press, 2002 